\title{
Topical anaesthesia for repair of minor lacerations
}

\author{
D H Bass, P J Wormald, J McNally, H Rode
}

Table 1 Scoring system for patients before and during suturing

\begin{tabular}{ll}
\hline Score & Behaviour \\
\hline 1 & $\begin{array}{l}\text { Crying and } \\
\text { requiring restraint } \\
\text { Crying not requiring } \\
\text { restraint }\end{array}$ \\
3 & $\begin{array}{l}\text { Calm and flinching } \\
\text { Calm and motionless }\end{array}$ \\
\hline
\end{tabular}
Department of Paediatric Surgery, Institute of Child Health, University of Cape Town and Red Cross War Memorial Children's Hospital

D H Bass

P J Wormald

J McNally

H Rode

Correspondence to: Dr D H Bass, Department of Paediatric Surgery, Red Cross War Memorial Children's Hospital Rondebosch 7700

Republic of South Africa.

Accepted 9 June 1990

(Arch Dis Child 1990;65:1272-4).

\begin{abstract}
One hundred traumatic skin wounds were sutured under topical anaesthesia using a solution of lignocaine, adrenaline, and cocaine, and the effectiveness of the anaesthesia produced was assessed on a behavioural scale. The procedure was tolerated well by 63 patients, poorly by 11 , and in 26 the response was uncertain. The response correlated well with age and with the field of anaesthesia measured from the wound margin. No toxic reactions were observed.
\end{abstract}

Minor lacerations resulting from falls, bumps, blows, or sharp objects are extremely common in young children. Often the most painful aspect of suture repair is the necessary infiltration of the wound margins with local anaesthesia, usually $1-2 \%$ solutions of lignocaine or amethocaine (tetracaine) hydrochloride. Suturing under topically applied solutions of amethocaine, adrenaline and cocaine has recently been described, ${ }^{1-3}$ and this method appears to provide adequate local anaesthesia while being accepted by the patients at least as well as lignocaine infiltration. The degree to which topical anaesthesia is tolerated by children, however, remains unclear. This is principally due to poorly defined subjective methods that have been used previously to evaluate the child's response to the suturing procedure. ${ }^{1-3}$

Using a simple but objective method of pain assessment, this prospective study was undertaken to assess whether a topical solution of lignocaine, adrenaline, and cocaine (LAC) provides adequate anaesthesia for the suturing of skin lacerations in children under 13 years of age.

\section{Patients and methods}

Between September 1989 and February 1990, consecutive patients seen by two registrars (PJW and JM) at The Red Cross War Memorial Children's Hospital trauma unit with skin lacerations requiring suturing were included in the study. Patients with multiple or crush injuries, human bites, wounds more than 24 hours old, and those with a history of seizures, or any form of cardiac disease, were excluded. Mechanism of injury as well as site, type, and length of wound were documented. The topical anaesthetic solution was made up by the hospital pharmacy in $50 \mathrm{ml}$ batches comprising $5.9 \mathrm{~g}$ cocaine $(11 \cdot 7 \%), 25 \mathrm{ml}$ adrenaline $(1: 1000), 0.5 \mathrm{~g}$ lignocaine $(1 \%)$, and normal saline to volume. The solution was stored at $15-20^{\circ} \mathrm{C}$ in a refrigerator specifically set aside for controlled drugs and has appeared to remain stable for up to three months.

A maximum volume of $3 \mathrm{ml}$ (330 mg cocaine) was dripped into each wound over a period of 90 seconds after which the wound was loosely covered for 12-15 minutes with a sterile dressing. In children old enough to cooperate the field of anaesthesia from the wound edge was then measured to pinprick. Thereafter the wounds were prepared with $5 \%$ povidone-iodine solution and debrided as necessary. All wounds were primarily closed with simple, interrupted nylon sutures. The patients' behaviour, before as well as during suturing, was scored on a scale of 1-4 (table 1) by both the registrar and a disinterested non-medical observer from outside the trauma unit. All patients were asked to return to the unit for wound inspection and removal of sutures.

\section{Results}

During the study period 100 patients ( 69 boys and 31 girls) presented with lacerations which were sutured under topical LAC anaesthesia. The mean age was 5 years with only two patients under 12 months. Eighty five wounds resulted from blunt trauma, 13 from sharp objects, and there were two dogbites. Eighty four of the wounds were on the scalp or face. Only 11 wounds were visibly contaminated with dirt. Wound length ranged from 5-80 mm with a mean length of $15 \mathrm{~mm}$. The field of anaesthesia could be assessed in 51 children and measured 3 $\mathrm{mm}$ or more in 43.

Out of a total of 100 registrar scores and 100 observer scores there was disagreement in only 12 instances of which eight were by one point only. As the discrepancy between the two sets of scores was so small, further analysis of results was performed using only the registrar's scores (table 2). The response of children who cried before and during suturing was considered to be uncertain. Partially because of unequal numbers in each category, there was no correlation between site, type, or length of wound and the children's behaviour. However, there was clearly an association between age, the field of anaes-

Table 2 Assessment of patients' behaviour according to doctors' score

\begin{tabular}{llll}
\hline $\begin{array}{l}\text { Before } \\
\text { suture }\end{array}$ & $\begin{array}{l}\text { During } \\
\text { suture }\end{array}$ & $\begin{array}{l}\text { Patient } \\
\text { response }\end{array}$ & $\begin{array}{l}\text { No of } \\
\text { children }\end{array}$ \\
\hline $1-2$ & $1-2$ & Uncertain & 26 \\
$1-2$ & $3-4$ & Good & 4 \\
$3-4$ & $3-4$ & Good & 59 \\
$3-4$ & $1-2$ & Poor & 11 \\
\hline
\end{tabular}


Table 3 Patient response by field of anaesthesia and age

\begin{tabular}{|c|c|c|c|c|}
\hline & \multicolumn{3}{|c|}{ Patient response } & \multirow{2}{*}{$\begin{array}{l}\text { No of } \\
\text { children }\end{array}$} \\
\hline & Good & Uncertain & Poor & \\
\hline $\begin{array}{l}\text { Field of anaesthes } \\
\text { Not measured } \\
0-1 \\
2 \\
3 \\
4 \\
5+\end{array}$ & $\begin{array}{l}\text { sia }(\mathrm{mn} \\
18 \\
0 \\
3 \\
10 \\
15 \\
17\end{array}$ & $\begin{array}{r}23 \\
1 \\
2 \\
0 \\
0 \\
0\end{array}$ & $\begin{array}{l}8 \\
0 \\
2 \\
1 \\
0 \\
0\end{array}$ & $\begin{array}{r}49 \\
1 \\
7 \\
11 \\
15 \\
17\end{array}$ \\
\hline Total & 63 & 26 & 11 & 100 \\
\hline $\begin{array}{l}\text { Age (years): } \\
<1 \\
1-4 \\
4-6 \\
>6\end{array}$ & $\begin{array}{r}0 \\
14 \\
17 \\
32\end{array}$ & $\begin{array}{r}2 \\
20 \\
4 \\
0\end{array}$ & $\begin{array}{l}0 \\
8 \\
2 \\
1\end{array}$ & $\begin{array}{r}2 \\
42 \\
23 \\
33\end{array}$ \\
\hline Total & 63 & 26 & 11 & 100 \\
\hline
\end{tabular}

thesia measured, and the way in which suturing was tolerated (table 3). Forty nine out of 56 children over 4 years but only 14 out of 44 under 4 tolerated the procedure well. Also, a field of anaesthesia of $3 \mathrm{~mm}$ or more almost uniformly predicted a good response. Field of anaesthesia could be measured in five out of six children with lacerations of the lower limb and equalled $4 \mathrm{~mm}$ or more in all five.

Seventy two children returned to follow up and four wounds (6\%) were clearly infected but had not dehisced. Pus swabs were taken from each wound and yield positive cultures for Staphylococcus aureus $(\mathrm{n}=2)$ and group A $\beta$ haemolytic streptococcus $(n=2)$. Each of these wounds were treated with suture removal and a topical antiseptic.

\section{Discussion}

Over the past two years we have sutured the vast majority of minor skin lacerations using topical LAC solution and have found overall that this regime is tolerated far better by children than when infiltration anaesthesia is used. Based on our experience we could not justify a comparison between topical LAC and lignocaine infiltration under trial conditions.

Long in use as the topical anaesthesia of choice for minor procedures on the nose, mouth, and pharynx, cocaine has recently been shown to be a safe and effective anaesthetic for use on the skin when combined with a vasoconstricting agent, usually adrenaline. ${ }^{1}$ Cocaine is, however, a controlled substance and LAC solution is therefore more expensive than the equivalent amount of $1 \%$ lignocacine necessary for anaesthesia of minor lacerations and routine use in adults is probably not cost effective. In children, the advantages of producing local anaesthesia without using a needle hardly needs elaboration.

The technique of LAC application that we have used differs from those described previously. ${ }^{3}$ Firstly, LAC was applied before the wound was prepared or irrigated so that minimal discomfort would be caused to the patient. Secondly, we slowly irrigated the wound with LAC to ensure maximal contact between the anaesthetic and the raw surface. Dressings, which could draw LAC out of the wound, were not applied. We believe that this technique ensured the best possible anaesthetic absorption at all sites including the lower limb. We are unable to explain the variation in fields of anaesthesia other than by psychic factors affecting the response to pinprick. The variation in the fields measured as well as the correlation between a wide field and a good patient response emphasises the importance of observing a standardised technique.

The evaluation of analgesic or anaesthetic medications in children remains a problem. ${ }^{4}$ Because pain is an entirely subjective phenomenon it is virtually impossible to measure, particularly in an acutely injured child where the perception of pain is coloured by the acute trauma itself, past experience of pain or hospital visits, and parental attitudes. ${ }^{5}$ In this study we used a simple observational measure of change in behaviour based on the premise that most children would cry or resist if they felt pain. The $94 \%$ agreement between the doctors' and observers' scores indicate that this method is acceptably valid for children of all ages and far less subjective than methods previously used in similar studies. ${ }^{1-3}$ Twenty two of the 26 children who cried before and during the procedure were less than 4 years old and while no conclusions could be drawn in this group, the favourable results in the older children suggest that the distress observed in the younger age group might have been largely due to psychogenic factors.

The toxic effects of cocaine primarily involve the central nervous system ranging from mild excitability to convulsions and respiratory arrest in severe cases. ${ }^{6}$ Toxic reactions have been described after application of cocaine to mucosal and burn surfaces ${ }^{3}$ but not skin lacerations when a maximum dose of $350 \mathrm{mg}$ cocaine per 3 ml solution used. ${ }^{12}$ The addition of adrenaline provides local vasoconstriction allowing minimal systemic absorption of cocaine. Although this effect might theoretically interfere with wound healing, we observed no instances of wound dehiscence and the sepsis rate of $6 \%$ was similar to that reported previously with topical cocaineadrenaline solutions. ${ }^{12}$

In conclusion, we believe that topical LAC provides good anaesthesia for the repair of minor lacerations in children and is therefore an acceptable alternative to traditional but painful infiltration anaesthesia.

The authors wish to thank Ms J Mellis for assistance with data collection and Ms R Hebler for typing the manuscript.

1 Pryor GJ, Kilpatrick WR, Opp DR. Local anaesthesia in minor lacerations: topical TAC vs lidocaine infiltration. Ann Emerg Med 1980;9:568-71.

2 Schaffer DJ. Clinical comparison of TAC anaesthetic with and without cocaine. Ann Emerg Med 1985;14:1077-80.

3 Bonadio WA, Wagner V. Efficacy of TAC topical anaesthesia for repair of paediatric lacerations. Am $\mathcal{J}$ Dis Child 1988;142:203-5.

4 McGrath PA. An assessment of children's pain: a review of behavioural, psysiological and direct scaling techniques. Pain 1987;1:147-76.

5 Poznanski EO. Children's reactions to pain: a psychiatrist's perspective. Clin Pediatr $(P$ hila $)$ 1976;15:1114-9.

6 Verlander J, Johns ME. The clinical use of cocaine. Otolaryngol Clin North Am 1981;14:521-31. 